\title{
AXONAL TRANSPORT MAINTAINS TASTE RESPONSES
}

\author{
BRUCE OAKLEY, JOYCE S. CHU and LEE B. JONES
}

Division of Biological Sciences, Neuroscience Laboratory Building, The University of Michigan, Ann Arbor, Mich. 48109 (U.S.A.)

(Accepted February 12th, 1981)

Key words: axonal transport - neurotrophic - colchicine - petrosal ganglion - electrophysiology — taste buds - gerbil - trophic dependency - glossopharyngeal nerve

\section{SUMMARY}

Transection of the gerbil's IXth nerve causes gustatory action potentials to decline in $1-6 \mathrm{~h}$; the rate of decline is a linear function of the length of the nerve stump remaining attached to the tongue ${ }^{18}$. To test the implication that taste discharge mechanisms depend upon axonal transport in the IXth nerve, we injected $40 \mathrm{nl}$ of $\left[{ }^{3} \mathrm{H}\right]$ leucine into the petrosal ganglion of one IXth nerve of the gerbil, Meriones unguiculatus. Subsequent liquid scintillation counting of the petrosal ganglion, IXth nerve segments, and representative areas of the tongue indicated that labeled materials were transported down the IXth nerve primarily to the vallate and ipsilateral foliate taste papillae of the tongue. A significant impairment of axonal transport and a substantial decline in summated IXth nerve taste responses occurred within 2-3 h after colchicine was applied to the IXth nerve trunk between the tongue and the petrosal ganglion. Similarly, cooling the IXth nerve with a $3-10^{\circ} \mathrm{C}$ thermocouple junction or metal probe impaired axonal transport and caused a taste response decline. Since impulse mechanisms of the nerve trunk continued to function distal to these sites of treatment, we concluded that the maintenance of taste discharges at the level of the taste bud depends upon unimpeded axonal transport.

\section{INTRODUCTION}

Receptor cells within taste buds are modified epithelial cells which make synaptic contact with the terminals of taste axons innervating the epithelium ${ }^{15}$. Like other epithelial cells, taste receptor cells turn over; their life span is about 6-10 days ${ }^{1,5,10}$. The gustatory nerve supply ${ }^{16}$ causes undifferentiated epithelial cells to form taste receptor cells. Additionally, the continued presence of this nerve supply is 
required to maintain the taste bud. Denervation causes degeneration of taste buds $\mathbf{s}^{\mathbf{9}, 13}$, 16,26 which may reappear as soon as 1-2 days after reinnervation of taste papillae 4 . Thus, the taste neuron is frequently cited as the classic example of a neuron which has a trophic role in the development and maintenance of the normal morphological, physiological and biochemical features of its end organ (for reviews, see refs. 22 and 23). Nonetheless, the mechanism of the trophic influence of neural innervation upon taste buds is still unknown. The prevailing view is that taste buds are induced by a trophic chemical transported down the taste axons to the tongue where the chemical is released to trigger the differentiation of epithelial cells into taste receptor cells. Morphological evidence exists for the presence, in the postsynaptic terminals of sensory axons, of vesicles which might release axonally transported substances. For example, electron microscopic radioautography demonstrated that IXth nerve sensory endings contained vesicles at the carotid body ${ }^{11}$. Indirect support for a trophic role in gustation of axonally transported materials is provided by the longer survival times of taste buds ${ }^{24}$ and taste responses ${ }^{18}$ with longer nerve stumps attached to the tongue. Taste bud degeneration was produced in other experiments by: (i) intraperitoneal injection of vincristine ${ }^{25}$; (ii) application of colchicine to the IXth nerve with moistened cotton ${ }^{8}$; or (iii) direct injection of colchicine into the rat vallate papilla ${ }^{21}$. Blockage of axonal transport was implicated, but direct toxic effects on taste bud cells could not be ruled out. Thus, although current evidence is consistent with the view that taste responses and taste buds are maintained by axonal transport, more direct evidence would be desirable.

The present research was undertaken to determine whether selective impairment of axonal transport would lead to impaired taste bud function. We chose the gerbil for examination because it had earlier been shown that transection of the IXth nerve rapidly produced a substantial decline in taste discharges without affecting impulse mechanisms in the IXth nerve trunk itself ${ }^{17}$. We reasoned that if axonal transport in the IXth nerve were important in maintaining taste responses, acute transport blockage caused by either colchicine treatment or cooling of the IXth nerve should result in a taste response decline like that produced by transection.

\section{MATERIALS AND METHODS}

One-hundred-and-twenty-four male and female Mongolian gerbils (Meriones unguiculatus), 3-8 months old, weighing between 44 and $78 \mathrm{~g}$ were used in this study. Gerbils were housed with littermates of the same sex and maintained on a daily cycle of $12 \mathrm{~h}$ light and $12 \mathrm{~h}$ dark.

Operative procedures. Gerbils were anesthetized with ketamine hydrochloride ( $325 \mathrm{mg} / \mathrm{kg}$ body weight i.m.), followed $30 \mathrm{~min}$ later by $0.07 \mathrm{ml}$ pentobarbital sodium $(5.0 \mathrm{mg} / \mathrm{ml}$, i.p.) with supplementary doses of ketamine or pentobarbital sodium as needed. A rectal thermocouple monitored the gerbil's body temperature, which was maintained at $37^{\circ} \mathrm{C}$ by a heating pad. The animal was secured to a head-holder which immobilized the skull and facilitated orientation of the neck to permit exposure of the IXth cranial nerve (glossopharyngeal nerve). A tracheal cannula was inserted and the 
submaxillary gland and digastric muscle were removed on one side to expose the IXth nerve. The petrosal ganglion was exposed by opening the bulla and chipping away the thin layer of bone near the stapedial artery.

Taste stimulation and recording. Solutions were allowed to flow over the tongue by means of a gravity flow system with a funnel reservoir located approximately $60 \mathrm{~cm}$ above the animal. The funnel emptied into coiled polyethylene tubing that passed through a vertical, water-heated, glass cylinder before ending within the gerbil's mouth. This counter-current heat-exchanging cylinder brought all taste and rinse solutions to $37^{\circ} \mathrm{C}$ as monitored by a thermocouple in the gerbil's mouth.

A 20-sec stimulation with reagent grade $0.3 \mathrm{M} \mathrm{NH}_{4} \mathrm{Cl}$ was alternated with $3 \mathrm{~min}$ and $40 \mathrm{sec}$ of distilled water rinse without interruption of the fluid flow over the tongue $(0.15-0.2 \mathrm{ml} / \mathrm{sec})$. Electrical activity was differentially recorded by placing the intact IXth nerve on one or two $100 \mu \mathrm{m}$ nichrome wire electrodes which led to a Grass P-9 or P-511 preamplifier. The head-holder was grounded. Multi-unit impulse activity was displayed on an oscilloscope and monitored by means of a loudspeaker. Responses were tape recorded and displayed on-line on a polygraph with the summation time constant (Grass 7P3A) set at $0.5 \mathrm{sec}$. A response was defined as the difference between the steady-state level of background activity to flowing distilled water at $37{ }^{\circ} \mathrm{C}$ and the peak of the summated discharge elicited by a taste solution.

Tritiated amino acids. A glass micropipette with a $20 \mu \mathrm{m}$ tip diameter was attached by cyanoacrylate glue to the shaft of a 1- $\mu 1$ Hamilton microsyringe. Forty $\mathrm{nl}$ of radiolabeled amino acid was taken up after the syringe was partially filled with mineral oil. Air gaps were avoided. Using a microdrive fixed to the syringe barrel, the tip of the pipette was driven into the center of the petrosal ganglion where it was left for $10 \mathrm{~min}$ before injection of the amino acid. The fine drive of the micromanipulator advanced the syringe plunger which ejected the radiolabel as monitored by observing the oil/water meniscus in the tip of the micropipette with a dissecting microscope. To reduce variation in the amount of radiolabel counted, we used a standard volume of 40 $\mathrm{nl}$ of $\left[{ }^{3} \mathrm{H}\right]$ leucine in Ringer's $(1 \mu \mathrm{Ci})$ injected by micropipette into the center of the ganglion. With such precautions it was generally possible to obtain animals whose ganglionic counts differed by less than one-half log unit. After injection, the micropipette remained in situ for $15-60$ min to minimize leakage of the radiolabel from the ganglion.

The experiments measured the distribution of radiolabelled substance in treated and untreated nerves after a given interval of time. Nerves were treated by transection, by ligation with a monofilament nylon thread, by application of Gelfoam soaked in $100 \mathrm{mM}$ colchicine or by cooling the nerve (Fig. 1). The cooling device consisted of 25gauge hypodermic tubing with a sharp U-bend. Methanol cooled by dry-ice was circulated through the tubing to bring a copper/constantan thermocouple junction extending from the tip of the U-tube to the desired temperature. The thermocouple junction formed a cold, flat, triangular plate which supported about $1 \mathrm{~mm}$ of the nerve. We used a continuous recording thermocouple meter (Bailey Instruments, BAT-4) and adjusted the flow-rate of the methanol to maintain the thermocouple junction at the desired temperature $\pm 2{ }^{\circ} \mathrm{C}$ for treatment periods lasting for up to $2 \mathrm{~h}$. Condensate was removed from the nerve as required. 


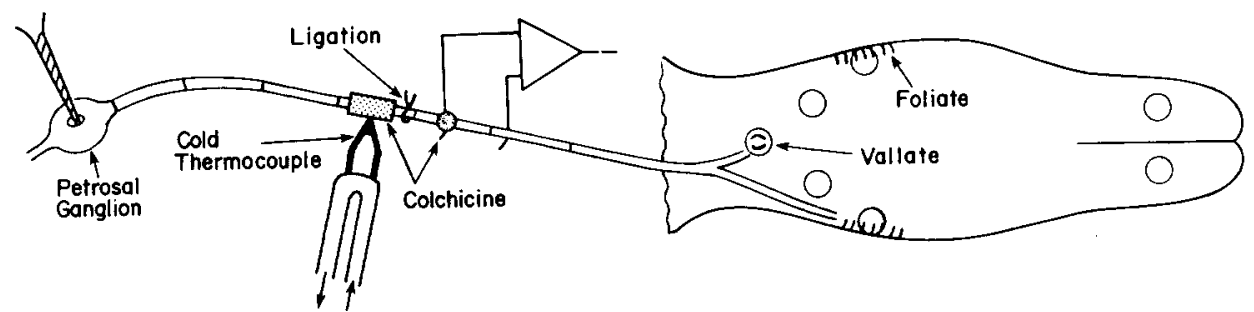

Fig. 1. Schematic drawing of the gerbil tongue and IXth nerve treatment sites, and $\left[{ }^{3} \mathrm{H}\right]$ amino acid injection into the petrosal ganglion. Colchicine was applied to the nerve either in a piece of Gelfoam sponge (axonal transport studies) or as a drop at the proximal recording electrode. Parallel arrows show the passage of cold methanol through a U-shaped piece of 25-gauge hypodermic tubing from which a thermocouple extends to touch nerve segment 4 . A $20-\mu \mathrm{m}$ monofilament nylon thread was used to ligate the nerve to block axonal transport. The 7 circular tongue biopsies are drawn to scale in size and position on the tongue.

The radiolabeled substances used in this experiment were either tritiated leucine, L-[3,4,5- $\left.{ }^{3} \mathrm{H}(\mathrm{N})\right]$ leucine (New England Nuclear, no. NET-460), spec. act. $110 \mathrm{Ci} / \mathrm{mmol}$, or in some instances a mixture of 15 tritiated L-amino acids (ICN no. 20063). In use, $\left[{ }^{3} \mathrm{H}\right]$ leucine and the tritiated amino acid mixture provided similar amounts of labeled nerve constituents. Once a week the radiolabeled stock solution was evaporated to dryness and redissolved in distilled water to the desired concentration $(1 \mu \mathrm{Ci} / 40 \mathrm{nl})$.

The experiments were terminated by flooding the surgical cavity with $10 \%$ trichloroacetic acid (TCA) for $10 \mathrm{~min}$. The nerve and attached ganglion were then removed and placed on a glass slide moistened with TCA. The ganglion was cut off and the nerve divided into 6 equal segments (approximately $1.2 \mathrm{~mm}$ each) which were transferred to individual scintillation vials containing $0.15 \mathrm{ml}$ of Beckman Tissue Solubilizer. In many animals 7 samples of the tongue were also obtained by placing the isolated tongue on a piece of dental baseplate wax and punching out a cylindrical core of the entire tongue thickness with a sharpened, cut off 18-gauge hypodermic needle. The sites assayed were the vallate papilla, the central folds of the foliate papillae, the area between the foliate and vallate papillae on both sides of the tongue and near the tip of the tongue (see circles on tongue in Fig. 1). Each tongue sample was placed in 2 $\mathrm{ml}$ of $10 \% \mathrm{TCA}$ for $10 \mathrm{~min}$ and then transferred to a scintillation vial with $0.15 \mathrm{ml}$ tissue solubilizer. After $24 \mathrm{~h} 1$ drop of stock hydrogen peroxide, 2 drops of glacial acetic acid, and $10 \mathrm{ml}$ of Beckman Ready-Solv EP were added to the vials. Counts were expressed as counts per minute (cpm) above background, with background typically $20-23 \mathrm{cpm}$. For each set of tissue samples background counts were assessed using a vial containing all constituents except animal tissue. Vials were kept in the dark for $24 \mathrm{~h}$ before counting with a Beckman LS 230 liquid sctintillation spectrometer. Appropriate corrections were made for quenching.

\section{RESULTS}

In attempting to relate axonal transport to taste function in the IXth nerve of the gerbil it was necessary to demonstrate that impaired axonal transport could be reliably detected. 
After injecting $40 \mathrm{nl}$ of leucine into the petrosal ganglion we compared radiolabel accumulation in 22 ligated and 31 untreated nerves over downflows ranging from 1 to $6 \mathrm{~h}$. A blockage of radiolabel movement occurred in 21 of 22 ligated nerves, and in only 3 of 31 untreated nerves as indicated by higher counts in nerve segment 4 than in segment 3, $(P<0.001$, Fisher Exact Probability Test $)$.

Accumulation of radiolabel at the ligated site is not attributable to diffusion since ligation at the same site failed to produce an accumulation of label in 6 animals killed by anesthetic overdose 16-77 min before $\left[{ }^{3} \mathrm{H}\right]$ leucine injection. Sacrificing the animals before $\left[{ }^{3} \mathrm{H}\right]$ leucine injection should have heightened the diffusion of radiolabel by maintaining higher levels of free $\left[{ }^{3} \mathrm{H}\right]$ leucine unincorporated into protein. As a further control, ligated nerves were treated along their exposed length with $0.5 \mathrm{ml}$ of vinblastine sulphate $(2 \mathrm{mg} / \mathrm{ml})$ for $30-60 \mathrm{~min}$. The vinblastine treatment eliminated radiolabel accumulation at the ligature.

In 8 animals the IXth nerve was cooled at segment 4 to $3-10{ }^{\circ} \mathrm{C}$ for $0.5-2 \mathrm{~h}$ following $2 \mathrm{~h}$ of downflow of labeled materials. This produced an accumulation in segment 3 significantly greater than in either untreated control nerves $(P=0.04$, Mann-Whitney U-test, $\mathrm{n}=14$ ) or in nerves maintained at $32-35^{\circ} \mathrm{C}$ by the thermal probe $(P=0.015$, Mann-Whitney U-test, $\mathrm{n}=13$ ) (Fig. 2). Fig. 2 additionally indicates that when the nerve was supported by the probe kept at a temperature of $32-35^{\circ} \mathrm{C}$, an accumulation in segment 4 occurred which was significantly greater than counts in segment 4 in untreated nerves $(P=0.004$, Mann-Whitney U-test, $\mathrm{n}=11)$. Apparently, the moderate cooling or the tension produced by suspending the intact nerve on the thermal probe was sufficient to cause some accumulation of label in the absence of intense cooling.

In the electrophysiological experiments cooling was carried out either by supporting the nerve on a cold thermocouple junction as described for the experiments

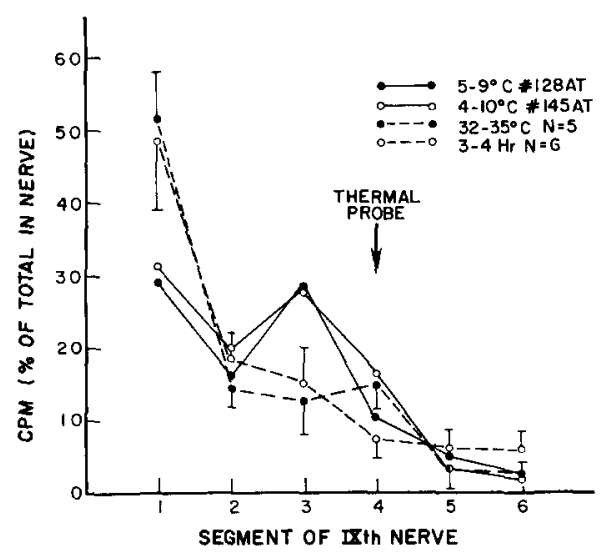

Fig. 2. Cooling the IXth nerve at segment 4 produced an accumulation of radiolabel at segment 3 (animal no. 128AT and no. 145AT) relative to untreated nerves (open circles and dashed lines, $\mathrm{X} \pm$ S.D., $n=6$ ) or nerves kept at $32-35^{\circ} \mathrm{C}$ by the thermal probe for $2 \mathrm{~h}$ after $1 \mathrm{~h}$ of normal downflow ( $\mathrm{X}$ \pm S.D., $n=5$ ). Counts per min for each nerve segment are given as a percentage of the total counts in the nerve. 


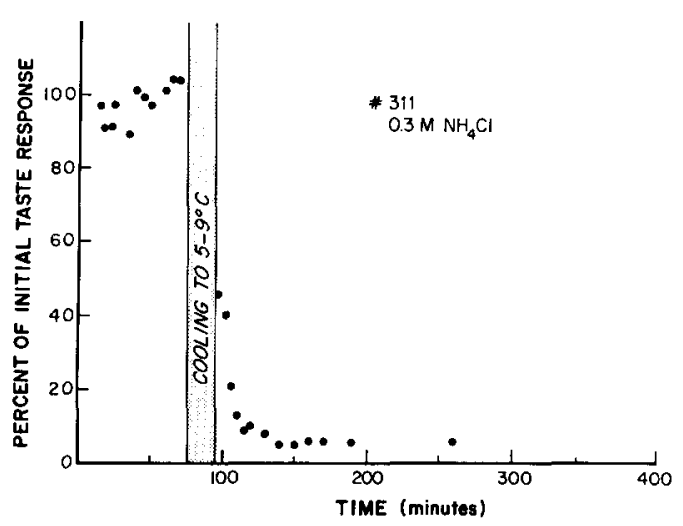

Fig. 3. The summated nerve discharges to $0.3 \mathrm{M} \mathrm{NH}_{4} \mathrm{Cl}$ applied to the tongue declined to less than $10 \%$ of their initial magnitude following $20 \mathrm{~min}$ of cooling of the IXth nerve to $5-9^{\circ} \mathrm{C}$.

with axonal transport or by contact with the bend of the U-shaped hypodermic tubing the temperature of which was monitored by a thermocouple junction located within the bend. Fifteen gerbils were tested by recording taste responses before and after cooling the IXth nerve to $3-10{ }^{\circ} \mathrm{C}$. Cooling durations varied from 15 to $60 \mathrm{~min}$. Cooling to $10^{\circ} \mathrm{C}$ for at least $15 \mathrm{~min}$ produced a decline in taste responses (Fig. 3). Rewarming the IXth nerve to $37{ }^{\circ} \mathrm{C}$ for $180 \mathrm{~min}$ resulted in partial recovery of gustatory function in 4 of 15 nerves.

To test the ability of locally applied colchicine to block axonal transport, a small piece of Gelfoam soaked in $100 \mathrm{mM}$ colchicine was applied for $2-4 \mathrm{~h}$ to segment 4 of the IXth nerve in 11 gerbils. As described in Methods, a single injection of $\left[{ }^{3} \mathrm{H}\right]$ leucine into the petrosal ganglion was given at times from $2 \mathrm{~h}$ before to $1 \mathrm{~h}$ after the beginning of colchicine treatment. Radiolabel accumulated in either segment 3 or segment 4 of all colchicine-treated nerves $(n=11)$, but not in untreated nerves or in nerves treated with Gelfoam soaked in Ringer's solution $(\mathrm{n}=7),(P<0.005$, Fisher Exact Probability Test).

In electrophysiological assessments of the effects of colchicine on gustatory discharges in 15 animals, the intact IXth nerve was suspended upon a pair of recording electrodes separated by $1.0 \mathrm{~mm}$. A small drop of colchicine $(0.5 \mu \mathrm{l})$ was applied at the proximal recording electrode. It was generally necessary to renew the colchicine drop occasionally during the course of the experiment. Summated responses of whole nerve taste discharges were measured in recording sessions which lasted for 300-400 min. A $50 \%$ or greater reduction in the taste response magnitude occurred in 0 of 4 nerves treated with $1.0 \mathrm{mM}$ colchicine, 2 of 5 nerves with $10 \mathrm{mM}$ colchicine and 5 of 6 nerves with $50 \mathrm{mM}$ colchicine (Fig. 4). The median time for the beginning of a response decline (10\% reduction) was $148 \mathrm{~min}$ with $50 \mathrm{mM}$ colchicine. In two animals, responses declined after treatment with one drop of colchicine; the smallest amount of colchicine observed to cause a response decline was $2 \mu \mathrm{g}$. In control experiments it was observed that drops of Locke's Ringer's on the recording electrode did not cause a taste response decline, and that soaking the IXth nerve in Locke's Ringer's solution for periods of up to $0.5 \mathrm{~h}$ after colchicine treatment did not improve a failing response. 


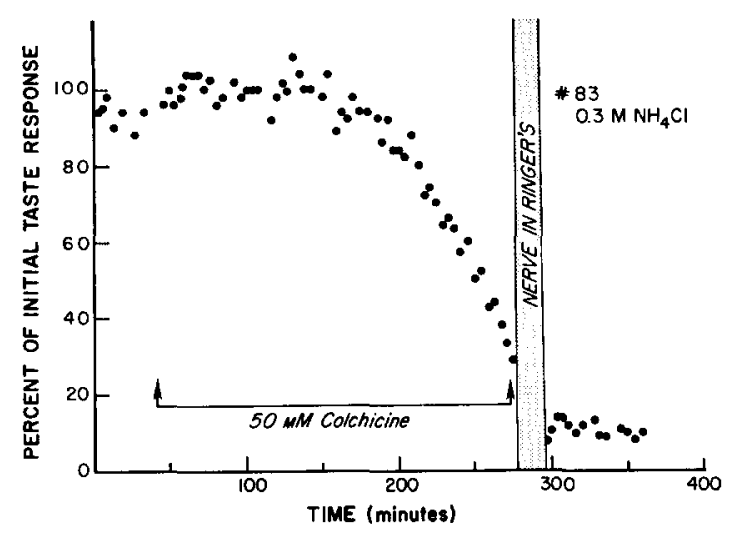

Fig. 4. The summated discharge of the whole IXth nerve to oral applications of $0.3 \mathrm{M} \mathrm{NH}{ }_{4} \mathrm{Cl}$ is expressed as a percentage of the initial taste response magnitude. One drop of $50 \mathrm{mM}$ colchicine on the nerve initiated a taste response decline which was not reversed by soaking the nerve in Ringer's solution.

We used a modified 18-gauge syringe needle to obtain tongue samples from the front of the tongue, the vallate papilla, the middle slits of the foliate papillae, and a region of the posterior tongue midway between the vallate and foliate papillae (see the location of circles in Fig. 1). With 3-4 h of downflow, counts were less than $10 \mathrm{cpm}$ above background at all tongue locations except the vallate and ipsilateral foliate papillae where counts were typically an order of magnitude greater. If the taste response decline in treated nerves resulted from impaired axonal transport, then there should have been a reduction in the delivery of radiolabeled materials to the vallate and ipsilateral foliate taste buds. Liquid scintillation counting of samples of the tongue revealed that counts in the vallate and ipsilateral foliate papillae were significantly reduced by treatment with colchicine ( $70 \%$ reduction, $n=4)$ and cooling $(64 \%$ reduction, $n=6)$ compared with untreated control nerves $(n=6)$. Thus, colchicine and cooling were shown to impair transport along the nerve, and decrease the delivery of labeled materials to the vallate and ipsilateral foliate papillae.

\section{DISCUSSION}

Control experiments with transected, ligated or vinblastine-treated nerves indicated that the net proximodistal flow of radiolabel in intact and transected IXth nerves occurred primarily by axonal transport rather than by diffusion or local circulation.

The decline of the taste response mechanism after cooling or colchicine treatment of the IXth nerve cannot be attributed to a deterioration of the impulse mechanism in the nerve trunk. One recording electrode was always located distal to the treatment site on the nerve. Spontaneous activity and a small residual taste response were often present at the close of a recording session. In nerves with little or no remaining taste response, compound action potentials could be elicited by electrical stimulation of the distal portion of either the transected nerve or the intact nerve 
treated by colchicine or by cooling ${ }^{18}$. Acute treatment with colchicine fails to disrupt impulse mechanisms of rabbit vagus nerve ${ }^{12}$. For these reasons we argue that the site of failure of the taste discharge lie not in the nerve trunk's impulse mechanisms but at the level of the taste bud.

Hence, local treatment of the intact IXth nerve with colchicine or cold-block impaired axonal transport, decreased the delivery of radiolabeled substances to the ipsilateral taste papillae, and triggered a progressive reduction in IXth nerve taste discharges. This suggests that axonal transport is necessary for the maintenance of the IXth nerve gustatory discharge in the gerbil.

It is interesting to compare the latency of the decline in the taste response following cooling, transection and colchicine. Nerve cooling generally produced a prompt decline in taste responses; the latency of response decline shown in Fig. 3 was among the most rapid observed with cooling. The cold probe typically cooled the IXth nerve to $5{ }^{\circ} \mathrm{C}$ at the point of contact, approximately $6 \mathrm{~mm}$ from the vallate papilla. Since temperatures below $11^{\circ} \mathrm{C}$ produce a complete block of fast axonal transport in mammalian nerves ${ }^{2,6,19}$, it is reasonable to assume that the longitudinal spread of cooling blocked axonal transport along several millimeters of the nerve. IXth nerve transection at $5 \mathrm{~mm}$ from the vallate papilla produced a $50 \%$ response decline in a mean of $45 \pm 9 \min (\bar{X} \pm \text { S.E. })^{18}$, whereas cooling caused a $50 \%$ response decline in a mean of $61 \pm 3.6 \mathrm{~min}$. Thus, this comparison indicates similar latencies to response decline after cooling and transection. In contrast to the rapid effects of cooling and transection, prolonged treatment with colchicine was generally required to initiate a taste response decline. That it required, on the average, 2.5 times longer for colchicine is probably attributable to the time needed to penetrate into the intact sheathed nerve and act upon the transport system. The nerve sheath is known to be a significant barrier, since in desheathed nerves, colchicine acts twice as fast to block transport ${ }^{12}$.

In vitro cooling of peripheral nerve to $10^{\circ} \mathrm{C}$ blocks axonal transport, e.g. of tritiated proteins in cat sciatic nerve ${ }^{19}$ and of dopamine beta-hydroxylase in rabbit sciatic nerve ${ }^{2,6}$. Within $1 \mathrm{~h}$ after rewarming the sciatic nerve to $37^{\circ} \mathrm{C}$ partial recovery of axonal transport occurs; transport velocity reaches $78 \%$ of normal ${ }^{19}$ and some but not all material moves from the site of nerve cooling ${ }^{6}$. Assuming axonal transport in the gustatory fibers of the intact IXth nerve recovers in a manner similar to the sciatic nerve, the absence of recovery of gustatory function in 11 of 15 nerves rewarmed to 37 ${ }^{\circ} \mathrm{C}$ for $3 \mathrm{~h}$ suggests that either irreversible changes occurred or the specific substances needed at the taste buds were being inadequately resupplied following cooling.

In the electrophysiological measurements, colchicine was applied as a single drop at the proximal recording electrode while the nerve was suspended in air. In two instances the application of a single drop at the electrode was sufficient to cause a reduction of the taste discharge. Hence, it seems unlikely that colchicine acted directly upon the taste buds to trigger the loss of these taste responses. Nevertheless, since colchicine is known to be highly toxic to excitable cells ${ }^{3}$, the possibility of direct action upon the taste buds cannot be completely excluded. Cooling the suspended IXth nerve should not have cooled the taste buds. The uninterrupted flow of $37{ }^{\circ} \mathrm{C}$ solutions (water or tastants) through the oral cavity continuously warmed the superficially 
located vallate papillae and the 3-4 mm of the IXth nerve within the tongue, thereby protecting this region from the cooling effect of the cold probe applied proximally to the suspended IXth nerve. On these grounds it is likely that cooling and probably colchicine triggered the reduction in taste discharges by impairing axonal transport in the nerve trunk.

Colchicine blockage of axonal transport in the optic nerve depresses synaptic transmission from the optic nerve to visual centers ${ }^{14,20}$. Since the first morphological change is a swelling of the presynaptic vesicles, at which time synaptic transmission but not impulse conduction is impaired ${ }^{7}$, it was concluded that the blockage of fast axonal transport by colchicine must depress synaptic transmission by disrupting the function of the presynaptic optic nerve fiber terminals ${ }^{14,20}$. In denervated mammalian taste buds the earliest morphological changes are seen in the axon terminals ${ }^{9}$. Consequently, in the present experiment, if the rapid decline of the taste responses results from a failure of the taste axon terminals, it would represent an instance of a dependence of the postsynaptic structures upon fast transport, since the receptor cells are the presynaptic structures.

The concurrent impairment of the taste responses and axonal transport in the IXth nerve by both colchicine trealment and by cooling of the IXth nerve indicates that taste response mechanisms have a continual dependence upon adequate axonal transport.

\section{AKCNOWLEDGEMENTS}

We are grateful to D. Berland, M. Hosley, J. Minier and H. Sloan for their valuable contributions.

\section{REFERENCES}

1 Beidler, L. M. and Smallman, R. L., Renewal of cells within taste buds, J. cell. Biol., 27 (1965) 263-272.

2 Brimijoin, S., Olsen, J. and Rosenson, R., Comparison of temperature-dependence of rapid axonal transport and microtubules in nerves of the rabbit and bullfrog, J. Physiol. (Lond.), 287 (1979) 303-314.

3 Cangiano, A. and Fried, J. A., The production of denervation-like changes in rat muscle by colchicine, without interference with axonal transport or muscle activity, J. Physiol. (Lond.), 265 (1977) 63-84.

4 Cheal, M. L. and Oakley, B., Regeneration of fungiform tastebuds: temporal and spatial characteristics, J. comp. Neurol., 172 (1977) 609-626.

5 Conger, A. D. and Wells, M. A., Radiation and aging effect on taste structure and function, Rad. Res., 37 (1969) 31-49.

6 Cosens, B., Thacker, D., and Brimijoin, S., Temperature-dependence of rapid axonal transport in sympathetic nerves of the rabbit, $J$. Neurobiol., 7 (1976) 339-354.

7 Cuénod, M., Sandri, C. and Akert, K., Enlarged synaptic vesicles in optic nerve terminals induced by intraocular injection of colchicine, Brain Research, 39 (1972) 285-296.

8 Donegani, G. and Filogamo, G., Sul comportamento dei recettori nelle papille foliate dopo trattamento con colchicina del nervo glosso-faringeo, nel coniglio, Soc. Ital. Biol. Sper. Boll., 47 (1971) 156-159.

9 Farbman, A. I., Fine structure of degenerating taste buds after denervation, J. Embryol. exp. Morph., 22 (1969) 55-68. 
10 Farbman, A. I., Renewal of taste bud cells in rat circumvallate papillae, Cell Tiss. Kinet., 13 (1980) 349-357.

11 Fidone, S J., Stensaas, L. J. and Zapata, P., Sensory nerve endings containing 'synaptic' vesicles - an electron-microscope autoradiographic study, J. Neurobiol., 6 (1975) 423-427.

12 Fink, B. R., Byers, M. R. and Middaugh, M. E., Dynamics of colchicine effects on rapid axonal transport and axonal morphology, Brain Research, 56 (1973) 299-311.

13 Guth, L., The effects of glossopharyngeal nerve transection on the circumvallate papilla of the rat, Anat. Rec., 128 (1957) 715-731.

14 Holmgren, E., Karlsson, J.-O. and Sjöstrand, J., Changes in synaptic function induced by blockage of axonal transport in the rabbit optic pathway, Brain Research, 157 (1978) 267-276.

15 Murray, R. G., Ultrastructure of taste receptors. In L. M. Beidler (Ed.), Handbook of Sensory Physiology, Vol IV, Chemical Senses, Part 2, Taste, Springer-Verlag, New York, 1971, pp. 31-50.

16 Oakley, B., On the specification of taste neurons in the rat tongue, Brain Research, 75 (1974) 85-96.

17 Oakley, B., Jones, L. B. and Hosley, M. A., Decline of IXth nerve taste responses following nerve transection, Chem. Senses Flav., 4 (1979) 287-299.

18 Oakley, B., Jones, L. B. and Hosley, M. A., The effect of nerve stump length upon mammalian taste responses, Brain Research, 194 (1980) 213-218.

19 Ochs, S. and Smith, C., Low temperature slowing and cold-block of fast axoplasmic transport in mammalian nerves in vitro, J. Neurobiol., 6 (1975) 85-102.

20 Periśić, M. and Cuénod, M., Synaptic transmission depressed by colchicine blockade of axoplasmic flow, Science, 175 (1972) 1140-1142.

21 Rodrigo Angulo, M. L., Fernández Sánches, B. and Rodríguez-Echandía, E. L., The reversible effect of colchicine on the taste bud cells of the central circumvallate papilla in the rat, Cell Tiss. Res., 192 (1978) 67-76.

22 Rosenthal, J., Trophic interactions of neurons. In E. R. Kandel (Ed.), Handbook of Physiology, Section I, The Nervous System, Vol. I. Part 2, American Physiological Society, Bethesda, 1977, pp. 775-802.

23 Smith, B. H. and Kreutzberg, G. W., Neuron-target cell interactions, Neurosci. Res. Progr. Bull., 14 (1976) 211-453.

24 State, F. A. and Dessouky, H. I., Effect of the length of the distal stump of transected nerve upon the rate of degeneration of taste buds, Acta anat. (Basal), 98 (1977) 353-360.

25 State, F. A., Hamed, M. S. and Bondok, A. A., Effect of vincristine on the histological structure of taste buds, Acta anat. (Basel), 99 (1977) 445-449.

26 Zalewski, A. A., Combined effects of testosterone and motor, sensory, or gustatory nerve reinnervation on the regeneration of taste buds in the rat, Exp. Neurol., 24 (1969) 285-297. 